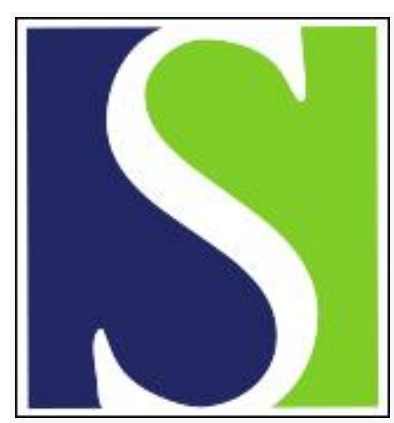

Scand J Work Environ Health 1984;10(2):95-98

https://doi.org/10.5271/sjweh.2359

Issue date: Apr 1984

A method for the determination of ethylenediamine in workroom air.

by Hansen L, Kristiansson B, Sollenberg J

This article in PubMed: www.ncbi.nlm.nih.gov/pubmed/6089328

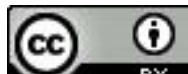




\title{
A method for the determination of ethylenediamine in workroom air
}

\author{
by Lars Hansén, MSc, Barbro Kristiansson, Jan Sollenberg, $\mathrm{PhD}^{1}$
}

\begin{abstract}
HANSÉN L, KRISTIANSSON B, SOLLENBERG J. A method for the determination of ethylenediamine in workroom air. Scand $J$ Work Environ Health 10 (1984) 95-98. An ethylenediamine-air mixture was generated in a dynamic gas mixing apparatus, and three different sampling techniques were tested. The analysis was performed using isotachophoresis. Sampling in an impinger flask containing hydrochloric acid $(20 \mathrm{mmol} / \mathrm{l})$ gave a quantitative recovery. Desorption losses were noticed when silica gel adsorption tubes were used. Cellulose filter support pads impregnated with oxalic acid were laborious to prepare, and the recovery was high only when freshly prepared filters were used. The use of impingers was found to be the most satisfactory method, and it was used for air monitoring in two factories handling ethylenediamine.
\end{abstract}

Key terms: dynamic gas standard, impingers, impregnated filters, isotachophoresis, silica gel tubes.

Ethylenediamine (EDA) is used as a solvent, an initial substance in organic synthesis (production of ethylenediaminetetraacetic acid), and in the rubber and pharmaceutical industries. EDA is a moderate skin irritant, and it can cause sensitization leading to allergic dermatitis and asthma $(3,7)$. The Swedish hygienic standard for EDA in the workroom environment is $25 \mathrm{mg} / \mathrm{m}^{3}$ (10 ppm). Using silica gel in glass tubes and analysis by gas chromatography, Vincent et al (8) have described a method for sampling EDA in air. They pointed out however that deterioration of the column material presents a problem. A method for air sampling on silica gel has been published by the National Institute for Occupational Safety and Health in the United States (5). To stabilize the amine, concentrated hydrochloric acid is added after sampling. Methanol-water is used for elution. After alkalinizing and reaction with benzaldehyde, the sample is analyzed by gas chromatography (5). Dalene et al (1) have described a method using a gas chromatograph equipped with a nitrogen sensitive detector for determining low molecular weight amines.

The production of EDA in Sweden is limited to a few chemical plants, and some chemical factories use EDA for the synthesis of other chemicals. Mostly the reaction is kept in a closed circulating system and partly located outdoors. On some occasions exposure may occur during filling and maintenance. These circumstances mean that only a small number of workers

\footnotetext{
National Board of Occupational Safety and Health, S-171 84 Solna, Sweden.
}

Reprint requests to: Dr $\mathrm{J}$ Sollenberg, Chemistry Department, National Board of Occupational Safety and Health, S-171 84 Solna, Sweden. are involved, and the demand for exposure measurements has been moderate.

As part of our investigations on analytical methods for amines used in industry, we describe the sampling and analysis of EDA in air. Three different sampling techniques were investigated: absorption in impigers, adsorption on silica gel, and adsorption on filter support pads impregnated with oxalic acid. The analyses were performed by isotachophoresis.

\section{Materials and methods}

\section{Preparation of gaseous standards}

A dynamic gas mixing system was constructed for EDA as shown in figure 1. The numbers and letters mentioned in the following paragraphs refer to this figure. In thermostated waterbath 1 gas washing bottle $2(30 \mathrm{ml})$ was placed containing EDA. A gentle stream of nitrogen from a gas cylinder was passed through. The flow was adjusted by needle valve $V_{1}$ and was observed on rotameter $R_{1}$. The EDA and nitrogen gas mixture was transported to dilution chamber $3(2,000 \mathrm{ml})$, made of polyethene. Compressed air was introduced through valve $V_{2}$ and split in two streams, one directly through rotameter $\mathrm{R}_{2}$ and into the dilution chamber and the other through flask 4 $(1,000 \mathrm{ml})$, containing water (flask filled to one-third with water). This stream was adjusted by valve $V_{3}$ and read on rotameter $R_{3}$. Thus the relative humidity could be varied from $0 \%$ to about $70 \%$. The humidified air was then passed through the dilution chamber. The saturated EDA gas (from 2) was diluted up to 10,000 times in this apparatus. The gas mixture was led into sampling chamber $5(500 \mathrm{ml}$, made 


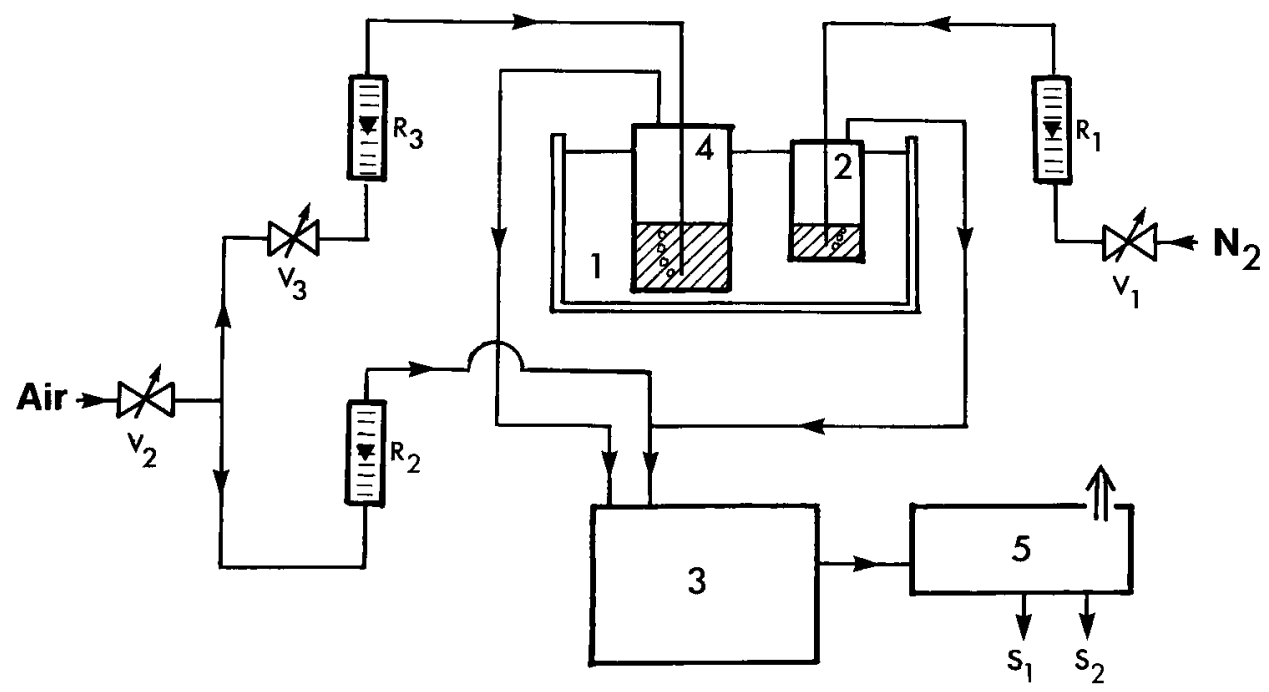

Figure 1. The dynamic gas mixing system used. $(1=$ waterbath, $2=$ gas washing bottle containing ethylenediamine, $3=$ dilution chamber, $4=$ humidifier, $5=$ sampling chamber, $R_{1}-R_{3}=$ rotameters, $S_{1}-S_{2}=$ sampling sites, and $V_{1}-V_{3}=$ needle valves, $\mathrm{N}_{2}=$ nitrogen)

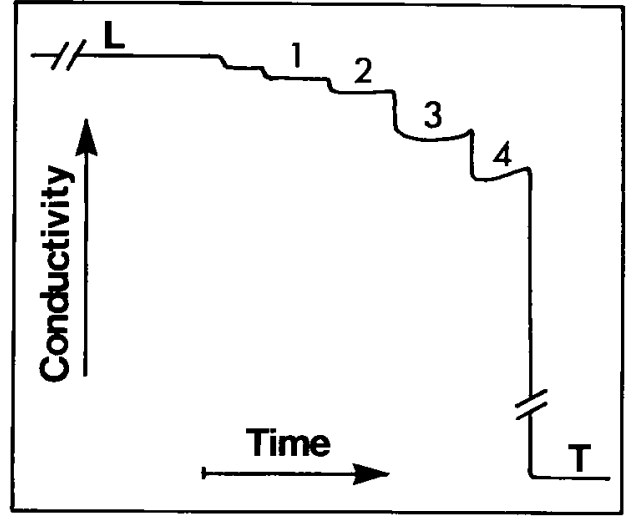

Figure 2. Isotachophoretic separation of a homologous series of amines (4 nmol of each) $[1=1,5$-diaminopentane, $2=$ 1,4-diaminobutane, $3=1,3$-diaminopropane, $4=1,2$-diaminoethane (EDA), $L=$ leading electrolyte, $T=$ terminating electrolyte, arrows $=$ relative conductivity and time (the length of the latter corresponds to $0.5 \mathrm{~min}$ in recording time)]

of polyethene), from which samples were taken. The surplus gas was emitted to the fume cupboard. The temperature and the relative humidity in the chamber was measured by a thermohygrometer (Vaisala OY, Helsinki, Finland).

The rotameters used were made by Rota (Rota Apparate- und Maschinenbau, Wehr, Federal Republic of Germany) and by Brooks (Brooks Instruments BV, Veenendaal, The Netherlands) and calibrated against a wet gas supply meter.

All the tubings (inner diameter $6 \mathrm{~mm}$ ) for the compressed air were made of polyvinyl chloride. The teflon tubing (inner diameter $2.2 \mathrm{~mm}$ ) between gas washing bottle 2 and dilution chamber 3 was as short as possible. The saturated EDA gas was led into the final part of the teflon tubing (inner diameter $9 \mathrm{~mm}$ ) which carried the dry air from $R_{2}$ into the dilution chamber, 3.

\section{Air sampling}

Air sampling was carried out with the three previously mentioned techniques.

Impingers. Samples were taken by the procedure of drawing the gas mixture through homemade impingers $(30 \mathrm{ml})$ of polystyrene containing $5 \mathrm{ml}$ of hydrochloric acid $(20 \mathrm{mmol} / \mathrm{l})$.

Adsorption tubes. Standard adsorption glass tubes (SKC Inc, Pittsburgh, Pennsylvania, the United States; outer diameter $6 \mathrm{~mm}$; length $70 \mathrm{~mm}$ ) with untreated silica gel in two adjacent sections, one of $150 \mathrm{mg}$ in a sorbent layer and one of $75 \mathrm{mg}$ in a backup layer, were used.

Impregnated filter. Cellulose support pads (Millipore Corp, Bedford, Massachusetts, the United States; diameter $25 \mathrm{~mm}$ ) were impregnated as described by Lindskog (4) $-0.4 \mathrm{ml}$ of oxalic acid $(0.4 \mathrm{mmol} / \mathrm{l})$ in ethanol containing $5 \%$ glycerol was evenly spread by a pipette on the surface of the pads in an oven at $70^{\circ} \mathrm{C}$. The pads were placed in a 25 -mm Millipore filter holder modified with an extra middle section to make it possible to hold two pads in series.

During the sampling the flow of standard gas was $150-200 \mathrm{ml} / \mathrm{min}$; it was continuously checked with a soap-bubbler flow meter connected to the outlet fitting of the pump. Personal portable pumps, MSA C-210 (Mine Safety Appliances Company, Pittsburgh, Pennsylvania, the United States) were used. 


\section{Desorption}

Desorption from the silica gel was performed by the transfer of each gel section from the tube to separate glass vials. One milliliter of a mixture of equal amounts of hydrochloric acid $(50 \mathrm{mmol} / \mathrm{l})$ and ethanol was added to the sorbent layer; $0.5 \mathrm{ml}$ of the same solution was added to the backup sorbent layer. The vials were then shaken for $30 \mathrm{~min}$ in a laboratory shaker.

\section{Analysis}

Up to $20 \mu 1$ of the absorption solution from the impinger flasks or of the extracts from the gels were then directly analyzed by isotachophoresis. The instrument used was an LKB 2127 Tachophor (LKBProdukter, Bromma, Sweden) equipped with a conductivity detector in the capillary tube (inner diameter $0.5 \mathrm{~mm}$, length $230 \mathrm{~mm}$ ) and thermostated at $23^{\circ} \mathrm{C}$. The migration current was $170 \mu \mathrm{A}$.

The leading electrolyte was prepared weekly and consisted of barium hydroxide $(5 \mathrm{mmol} / \mathrm{l})$ in $0.4 \%$ (weight/volume) hydroxypropylmethylcellulose (Dow Chemicals, Midland, Michigan, the United States). The $\mathrm{pH}$ of the solution was adjusted to 9.6 with $\beta$ alanine (Sigma, St, Louis, Missouri, the United States).

The terminating electrolyte was tris(hydroxymethyl)aminomethane $(20 \mathrm{mmol} / \mathrm{l})$ in hydrochloric acid (5 $\mathrm{mmol} / \mathrm{l}$ ), $\mathrm{pH} 8.7$.

The time of analysis was generally 7 to $10 \mathrm{~min}$.

\section{Results and discussion}

The dissociation constants of EDA at $25^{\circ} \mathrm{C}$ are 6.8 and 9.9 , respectively (6). The $\mathrm{pH}$ of the leading electrolyte was chosen in the vicinity of the latter. The electrolyte system was a variant of one of those presented by Hjalmarsson \& Baldesten (2). The system was tested on a mixture of four amines in a homologous series. At pH 9.6 the separation was found to be satisfactory (figure 2). A calibration curve was made for EDA in a water solution. It was linear in the range tested, $1-200 \mathrm{nmol}$ injected.

The results from the recovery studies made in the laboratory are shown in table 1 .

EDA was generated at two levels, one about half or less than the hygienic standard and the other from the hygienic standard up to twice its value. The sampling times were varied from $10 \mathrm{~min}$ to $4 \mathrm{~h}$.

As shown in the table, impingers gave a quantitative recovery at both levels. By recovery we mean the quotient of the EDA concentration determined by isotachophoresis and the calculated concentration of EDA standard based on the vapor pressure value (9) at the prevailing temperature. The uncertainty of the estimations include the errors from the gas standard preparation, sampling, desorption, and analysis.

Since impingers might be uncomfortable to use for personal sampling, we also tried silica gel tubes and filter support pads impregnated with oxalic acid. The silica gel tubes gave lower recoveries than the impinger flasks. The use of a cupric chloride solution or concentrated hydrochloric acid to increase the desorption efficiency has previously been reported ( 5 , 8). However this treatment could not be used in combination with isotachophoresis as the ionic strength of the resulting eluate was too high.

In our experiment the impregnated filter support pads gave satisfactory recoveries, but there are some disadvantages with this technique. The pads are laborious to prepare, and remarkably lower recoveries were obtained when they were prepared more than one week before the sampling. It is also desirable to modify the filter holder to allow a second filter for controlling breakthrough.

Thus, in our opinion, the use of impingers in combination with isotachophoresis gives a simple and reliable method for determining the level of EDA in workroom air.

The impinger sampling method has been used in two chemical factories handling EDA. One was a petrochemical plant producing EDA and five other amines, and the other was a factory using EDA for making ethylenediaminetetraacetic acid. A mixture of the six amines from the chemical plant was made in aqueous solution and was run in the electrolyte system. The separation is shown in figure 3 .

In these investigations EDA was found only at a site for tanking which occurred under a ventilation hood. The EDA concentration in the air was about $1 \mathrm{mg} / \mathrm{m}^{3}$ after $3 \mathrm{~h}$ of sampling at $750 \mathrm{ml} / \mathrm{min}$. With this method we also detected gaseous ammonia from a leaking pump placed outdoors in the production plant.

Table 1. Recovery experiments for ethylenediamine (EDA), generated by a dynamic gas system, and sampling with three different techiques.

\begin{tabular}{|c|c|c|c|c|c|c|c|}
\hline \multirow{3}{*}{$\begin{array}{l}\text { Estimated concentration } \\
\text { of EDA generated } \\
\quad\left(\mathrm{mg} / \mathrm{m}^{3}\right)\end{array}$} & \multirow{3}{*}{$\begin{array}{c}\text { Estimated amount } \\
\text { of EDA generated } \\
(\mu \mathrm{g} / \text { sample })\end{array}$} & \multicolumn{6}{|c|}{ Recovery percentage } \\
\hline & & \multicolumn{2}{|c|}{ Impinger } & \multicolumn{2}{|c|}{ Silica gel } & \multicolumn{2}{|c|}{ Oxalic acid filter } \\
\hline & & Mean & SD & Mean & SD & Mean & SD \\
\hline $3-11$ & $40-180$ & \multirow{2}{*}{\multicolumn{2}{|c|}{$\begin{array}{c}102.3={ }^{3.7} \\
(\mathrm{~N}=6) \\
97.6=15.0 \\
(\mathrm{~N}=8)\end{array}$}} & \multirow{2}{*}{\multicolumn{2}{|c|}{$\begin{array}{c}85.8 \quad{ }^{8.6} \\
75.0=6)^{13.7} \\
(N=8)\end{array}$}} & \multirow{2}{*}{\multicolumn{2}{|c|}{$\begin{array}{c}109.8=6.8 \\
(N=6)^{8.8} \\
89.4=23.2 \\
(N=9)\end{array}$}} \\
\hline $21-52$ & $120-1,650$ & & & & & & \\
\hline
\end{tabular}




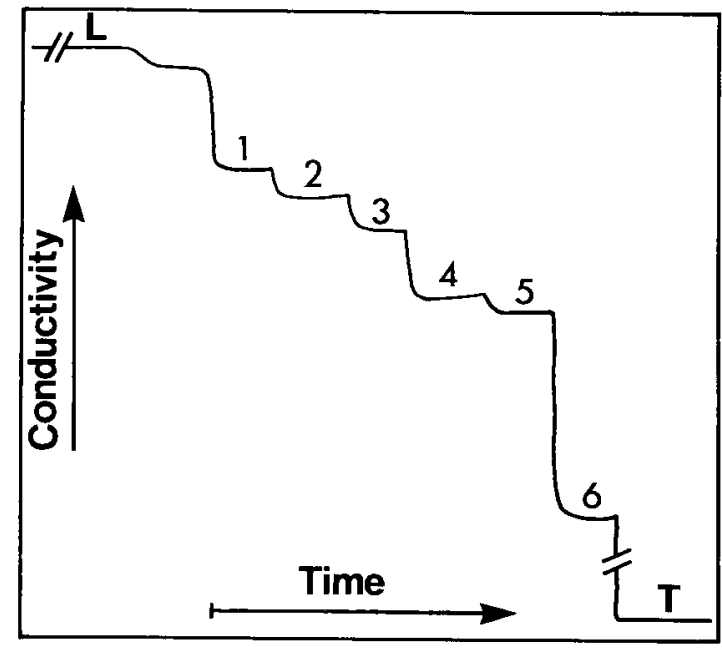

Figure 3. Isotachophoretic separation of six amines $(4 \mathrm{nmol}$ of each) from a petrochemical plant. $[1=1,2$-diaminoethane $(\mathrm{EDA}), 2=$ diethylenetriamine, $3=2$-aminoethanol, $4=$ 1-(2-aminoethyl)-piperazine, $5=\mathrm{N}$-(2-aminoethyl)-ethanolamine, $6=1$-(2-hydroxyethyl)-piperazine, $\mathrm{L}=$ leading electro lyte, $\mathrm{T}=$ terminating electrolyte, arrows $=$ relative conduct $\mathrm{i}$ vity and time (the length of the latter corresponds to $0.5 \mathrm{~min}$ in recording time)]

Isotachophoresis is an attractive technique because the samples can be analyzed directly from the absorption solution (without derivatization). If adequate buffer solutions are chosen, interfering substances from the air samples can be excluded. Thus noncomplex detection signals are obtained only from water-soluble cations having mobility at $\mathrm{pH} 9.6$.
A practical detection limit for the present method is $1 \mathrm{nmol}$ of EDA injected into the isotachophoresis instrument. This level corresponds to the sampling of 0.61 of air at an EDA concentration of $25 \mathrm{mg} / \mathrm{m}^{3}$ ( = hygienic standard). If necessary the sensitivity can be increased by the process of concentrating the absorption solution.

\section{References}

1. Dalene M, Mathiasson L, Jönsson JA. Trace analysis of free amines by gas-liquid chromatography. J Chromatogr 207 (1981) 37-46.

2. Hjalmarsson S-G, Baldesten A. A critical review of capillary isotachophoresis. CRC Crit Rev Anal Chem 11 (1981) $261-352$.

3. Lam S, Chan-Yeung M. Ethylenediamine-induced asthma Am Rev Respir Dis 121 (1980) 151-155.

4. Lindskog A. Rapport no 79/344. Swedish Work Environment Fund, Stockholm 1979. (In Swedish).

5. National Institute for Occupational Safety and Health. Manual of analytical methods. Second edition, volume 4 (Method no 276). US Department of Health, Education and Welfare, Washington, DC 1978.

6. Perrin DD. Dissociation constants of organic bases in aqueous solutions. Butterworths, London 1972. (International Union of Pure and Applied Chemistry supplement 1972).

7. Pevny I, Schäfter U. Äthylendiamin-Allergie. Dermatosen Beruf Umwelt 28 (1980) 35-40.

8. Vincent WJ, Hahn KJ, Ketcham NH. Monotoring personal exposure to ethylenediamine in the occupational environment. Am Ind Hyg Assoc J 40 (1979) 512-516.

9. Weast RC, ed. CRC handbook of chemistry and physics. 58th edition. CRC Press Inc, Cleveland, OH 1978.

Received for publication: 28 October 1983 